\title{
Laparoscopic Box Training with Four Different Modules in a Tertiary Education and Research Hospital, Ankara, Turkey
}

\author{
Omer L. Tapisiz ${ }^{1}$ Sadiman Kiykac Altinbas ${ }^{1} \quad$ Ozlem Moraloglu Tekin ${ }^{1}$
}

\author{
${ }^{1}$ Department of Obstetrics and Gynecology, University of Health \\ Sciences, Etlik Zubeyde Hanim Women's Health Training and \\ Research Hospital, Ankara, Turkey
}

Rev Bras Ginecol Obstet 2019;41:273-276.

\section{Dear Editor,}

Laparoscopic surgery (LS) has had a fundamental role in gynecology over the past 2 decades. Because LS is now widely accepted, training residents to perform laparoscopic procedures is essential. ${ }^{1}$ Therefore, simultaneously, the interest in training programs to teach technical skills is gaining ground rapidly. ${ }^{2,3}$ Laparoscopic surgery has obtained a major position within surgical specialties. For LS, additional psychomotor and hand-eye coordination skills are needed. ${ }^{4}$ To learn these skills, effective preclinical simple box trainers have been developed. In the light of these data, we have created a well-designed LS training room ( $\boldsymbol{- F i g . 1}$ ), and arranged four different modules. Here, we would like to present the LS training room and box trainers of our hospital, and also

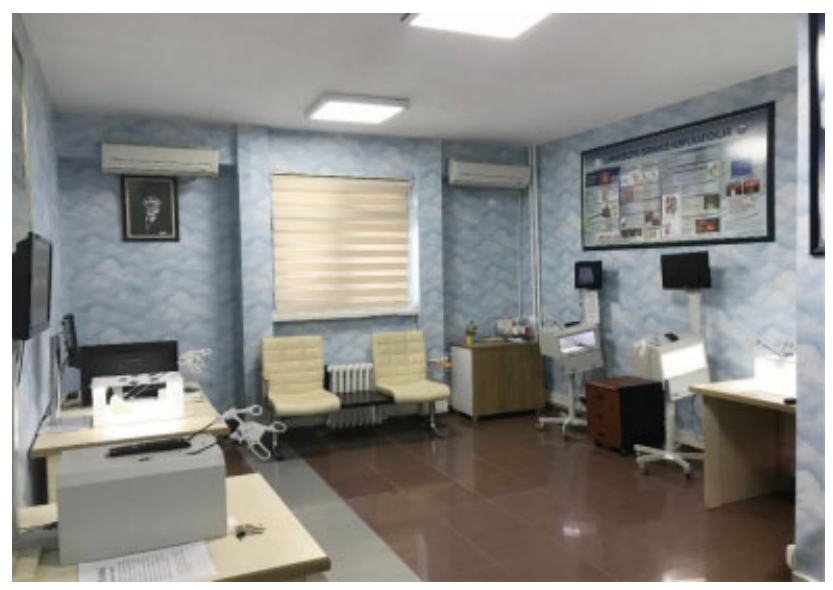

Fig. 1 View of the laparoscopic training room.

Note: The present study was presented as a poster presentation at ESGE $27^{\text {TH }}$ Annual Congress, $7^{\text {th }}-10^{\text {th }}$ October 2018, Vienna, Austria.

(D) Omer Lutfi Tapisiz's ORCID is https://orcid.org/0000-0002-71288086.
Address for correspondence Omer Lutfi Tapisiz, Md, PhD, Department of Obstetrics and Gynecology, University of Health Sciences, Etlik Zubeyde Hanim Women's Health Training and Research Hospital, Ankara, Turkey (e-mail: omertapisiz@yahoo.com.tr).

indicate the importance of these training activities in the education of the residents.

In $\boldsymbol{\sim}$ Fig. 2 , the training module (TM) 1 is presented. In this $\mathrm{TM}$, the surgeon should attach the rings to the nails while

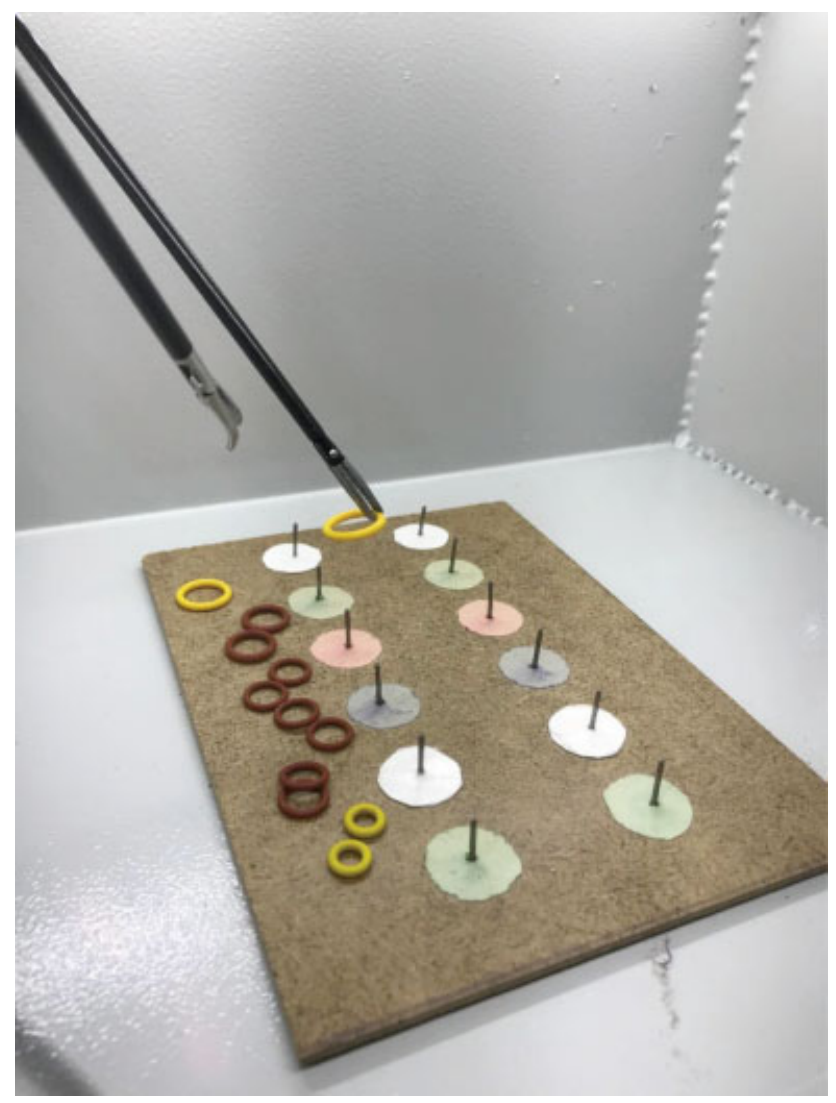

Fig. 2 Training module 1.

Copyright $\odot 2019$ by Thieme Revinter Publicações Ltda, Rio de Janeiro, Brazil 


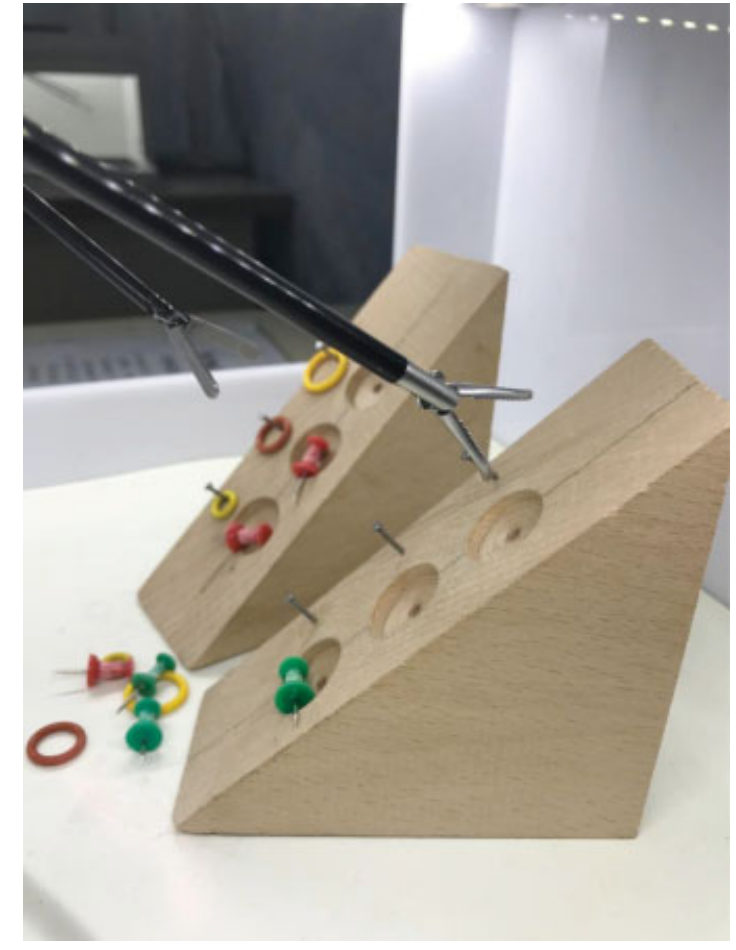

Fig. 3 Training module 2 .

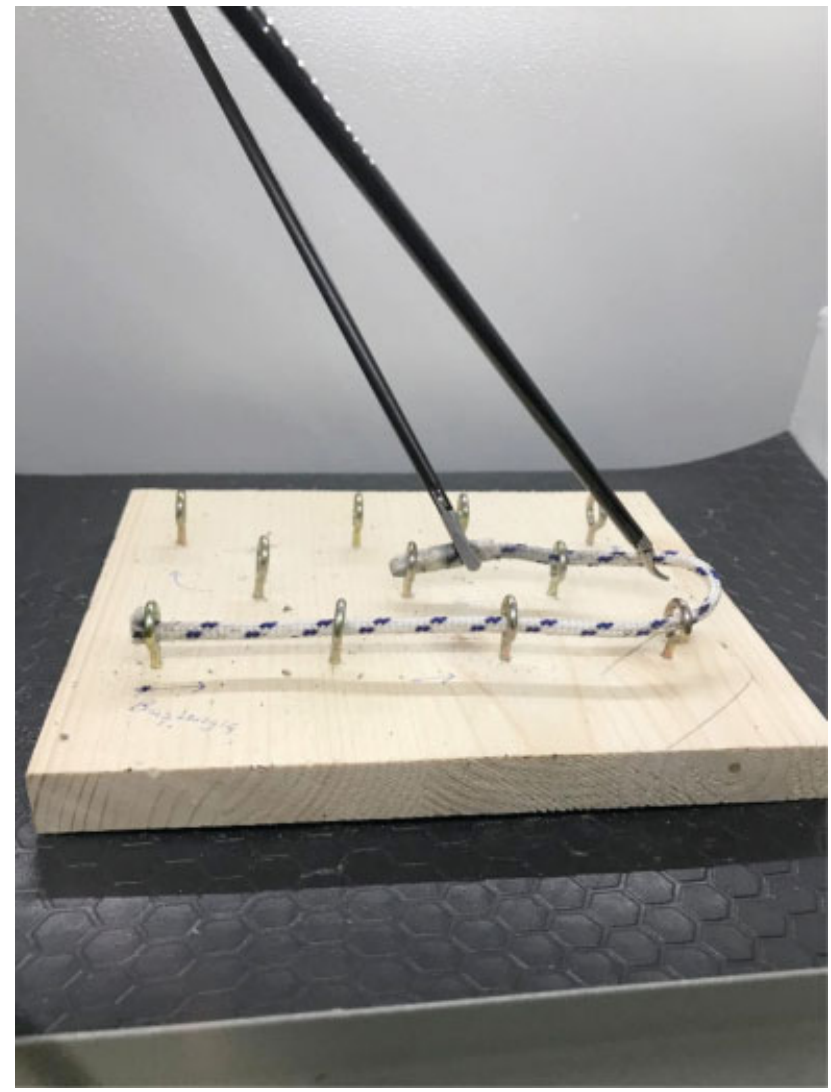

Fig. 5 Training module 4.

paying attention to their colors and sizes. In this process, the surgeon should also change the rings between the right and left hands.

In - Fig. 3, the TM 2 is presented. In this TM, the surgeon should place the pins in wooden hollows while paying attention to their colors. In this process, the surgeon should first pick the pins up from their color parts, then change them between the right and left hands by holding the needle part.

In - Fig. 4, the TM 3 is presented. In this TM, the surgeon should attach the small plastic pipes to the nails while paying attention to their colors.

In - Fig. 5, the TM 4 is presented. In this TM, the surgeon should pass the rope through the metal rings with the help of both hands. The direction should be from left to right and down/up to up/down.

In our opinion, for the development of effective and complete laparoscopic training programs, these integrated modules can be a practical answer. All these TMs improve the laparoscopic skills, and training with a virtual reality simulator or box trainer should be considered before actual laparoscopic procedures are performed. Therefore, it should be kept in mind that laparoscopic training hospitals should coordinate a laparoscopic training room that includes a traditional box trainer or with both box trainers and a virtual reality simulator.

\section{Conflicts of Interests}

The authors have no conflicts of interests to declare.

Fig. 4 Training module 3. 


\section{References}

1 Akdemir A, Sendağ F, Oztekin MK. Laparoscopic virtual reality simulator and box trainer in gynecology. Int J Gynaecol Obstet 2014;125(02):181-185. Doi: 10.1016/j.ijgo.2013.10.018

2 Shore EM, Grantcharov TP, Husslein H, et al. Validating a standardized laparoscopy curriculum for gynecology residents: a randomized controlled trial. Am J Obstet Gynecol 2016;215 (02):204.e1-204.e11. Doi: 10.1016/j.ajog.2016.04.037
3 Bharathan R, Setchell T, Miskry T, Darzi A, Aggarwal R. Gynecologic endoscopy skills training and assessment: review. J Minim Invasive Gynecol 2014;21(01):28-43. Doi: 10.1016/j. jmig.2013.07.016

4 Borahay MA, Jackson M, Tapısız OL, et al. Assessment of minimally invasive surgical skills of pre-medical students: What can we learn from future learners? J Turk Ger Gynecol Assoc 2014;15(02): 69-73. Doi: 10.5152/jtgga.2014.0044 